\title{
Feasibility and Sustainability of Community Based Health Insurance in Rural Areas. Case Study of Musana, Zimbabwe
}

\author{
Lazarus MUCHABAIWA*, Lloyd CHIGUSIWA, Samuel BINDU, \\ Victoria MUDAVANHU, David DAMIYANO \\ and Bongani Edwin MUSHANYURI
}

Bindura University of Science Education, Zimbabwe

\begin{abstract}
The Zimbabwe Demographic Health Survey (ZDHS 2010-11) showed that only 6 percent of the population is covered by health insurance in Zimbabwe. This study investigated the feasibility, acceptability and sustainability of Community Based Health Insurance (CBHI) as an alternative to pooling risk and financing social protection in Zimbabwe. Willingness to Pay (WTP) for health insurance and socioeconomic data were collected through interviews with 121 household heads selected using a 2-stage sampling procedure on 14 villages in Musana and Domboshava rural areas, a population which is largely unemployed and reliant on subsistence agriculture. A CBHI scheme was established and followed up for 3 years documenting data on visits made, financial contributions from recruited households and their actual health expenditures. Findings indicate that CBHI is generally accepted as a means of health insurance in rural communities. The median willingness to pay for health insurance was $\$ 5.43$ against monthly expenditures ranging of up to $\$ 180$. The low WTP is attributable to low incomes as only 3.4 percent of the respondents relied on formal employment. Trust issues, adverse selection, moral hazard, and administration costs were challenges threatening sustainability of CBHI. A financial gap averaging $42 \%$ was generally on a downward trend and was closed by the end of the follow-up study as contributions were equivalent to medical expenses. We conclude that CBHI is feasible, has potential for sustainability and should be considered as a springboard for the planned Zimbabwean National Health Insurance.
\end{abstract}

Keywords: Health Financing, Community Based Health Insurance, Social Protection

JEL Classification: I13, I15, I18

\footnotetext{
${ }^{*}$ Corresponding Author:

Lazarus Muchabaiwa, Bindura University of Science Education, Economics Department, P. Bag 1020, Bindura, Zimbabwe
}

Article History:

Received 22 June 2017 | Accepted 6 December 2017 | Available Online 15 December 2017

Cite Reference:

Muchabaiwa, L., Chigusiwa, L., Bindu, S., Mudavanhu, V., Damiyano, D. and Mushanyuri, B.E., 2017. Feasibility and Sustainability of Community Based Health Insurance in Rural Areas. Case Study of Musana, Zimbabwe. Expert Journal of Finance, 5, pp. 73-85 


\section{Introduction}

Universal coverage is regarded as fundamental to poverty reduction strategies (Summers, 2015; Tangcharoensathien et al., 2015; WHO, 2014). Out of pocket payment for accessing healthcare is a barrier to even basic health services. It has been established that out of pocket health expenditures condemn low income households into financial catastrophe (Ji et al., 2017; Jan et al., 2016; WHO, 2014). Consequently, such households find themselves trapped in the vicious circle of poverty due to the inability to work because of poor health. User fees thus derail universal health coverage efforts regarded as fundamental to poverty reduction strategies (Bhageerathy et al., 2017; WHO, 2014). Through risk pooling, health insurance is the best way towards attaining universal coverage. Health insurance provides financial protection when need for healthcare arises. Health insurance addresses equity in two ways. Firstly, the healthy subsidise those who fall ill more frequently. In addition to that, an effective health insurance will have low prepayments within the reach of the poor (WHO, 2014; Ahuja and Jutting, 2003). This ensures that even the poor can access conventional healthcare.

Low cost health insurance to low income households is one innovative method of financing healthcare, avoiding catastrophic out of pocket expenditures and increasing health access (Ji et al., 2017; Bhageerathy et al., 2017; Jan et al., 2016; GoZ, 2010). Health insurance allows risk pooling and provides financial protection when need for healthcare utilisation actually arises. It also addresses equity in two ways. Firstly, the healthy subsidise those who fall ill more frequently. In addition to that, an effective health insurance will have low prepayments within the reach of the poor. This ensures that even the poor can access healthcare.

In Zimbabwe, private health insurance markets which exist are biased towards the formal working class with premiums starting from $\$ 10$ per head. Consequently, the majority of Zimbabweans who are informally employed or unemployed are uncovered for medical expense uncertainty given unemployment rates above 90 per cent in Zimbabwe (Staunton, 2016). This is supported by data in the 2010-11 ZDHS showing that $94 \%$ of the Zimbabwean population has no health insurance cover.

Although the Zimbabwean government committed to allocate $15 \%$ of the national budget to finance healthcare in the Medium Term Plan (2011- 2015), government tax revenue financing is usually constrained by insufficient levels of revenue (GoZ, 2010). This implies that few resources are thinly spread across the whole population, leading to congestion at public health facilities or simply poor quality care. Furthermore, this commitment does not translate into removal of user fees introduced during the Economic Structural Adjustment Programme (ESAP) of 1991.

\subsection{Zimbabwe Health Insurance Background}

The 2015 National Health Accounts study showed that 26\% of health Services in Zimbabwe are financed from household out of pocket payments, $21 \%$ from the national budget allocation, $16 \%$ through private health insurance schemes, $15 \%$ from foreign aid and the rest from private corporations and nongovernmental organizations (GoZ, 2016). Out of Pocket payments date back to the Economic Structural Adjustment Programme (ESAP) of 1991 when the government implemented cost recovery measures in order to reduce spending in social services (Osaki et al., 2010). Consequently, health centres in low income rural areas suffered from shortage of essential drugs, deteriorating health facilities, reduced maintenance of equipment, rise in cost of health, decrease in healthcare spending by the low income earners, brain drain, and reduction in access to healthcare (Dhliwayo, 2001; Nanda, 2002).

The regime of user fees has resulted in national averages for consultation fees as shown in table 1. They show consultation fees ranging from $\$ 1$ to $\$ 11$. These figures are exclusive of medicine, bed, tests and procedures. Rural health centres charge the least consultation fee followed by mission hospitals which charge lower than private health clinics.

Table 1. Average Consultation Fee in US\$ for Adults

\begin{tabular}{|c|c|c|}
\hline Facility & Average adult Consultation Fee & Range \\
\hline Central Hospital & 9.75 & $8-11$ \\
\hline Provincial Hospital & 5.5 & $5-10$ \\
\hline District Hospital & 4.1 & $4-5$ \\
\hline Mission Hospital & 3 & $1-4$ \\
\hline Private Health Clinic & 4 & $3-5$ \\
\hline Rural Health Centre & 1 & $1-1$ \\
\hline
\end{tabular}

Adapted from Osaki et al. (2010) 


\begin{tabular}{|l|l|}
\hline \multicolumn{2}{|c|}{ Type } \\
\hline \multicolumn{1}{|c|}{ Table 2. Health Insurance Schemes in Zimbabwe } \\
\hline Employer Managed Funds & \multicolumn{1}{c|}{ Coverage } \\
\hline Medical Aid & Covers employees and their dependents only \\
\hline Health insurance Accounts & $\begin{array}{l}\text { National level; favours formal employees who contribute } \\
\text { periodically through direct payments from employer }\end{array}$ \\
\hline Combo- Health plus other insurance plan & $\begin{array}{l}\text { National; individuals place funds in a savings account held } \\
\text { by an insurance company }\end{array}$ \\
\hline & $\begin{array}{l}\text { National; Health insurance is combined with other } \\
\text { insurance plans like car/home }\end{array}$ \\
\hline
\end{tabular}

Adapted from Osaki et al. (2010)

Health insurance schemes have expanded in scope since the 1990s reforms. At present, they exist in different forms as presented in table 2 . These schemes are largely in favour of those formally employed for which direct payments can be made on a regular basis. Health insurance accounts would be more favourable to those with unstable incomes; however, it lacks the element of risk pooling.

The Zimbabwean government has proposed a national health insurance scheme (Share, 2016; GoZ, 2016) which has been used successfully in developed countries would be the most desirable in that it covers even those who cannot pay premiums. However, health insurance requires a relatively large working population in order to subsidise the unemployed, a challenge given the current unemployment rates in the country as well as high organizational capacity (Ji et al., 2017). One of the feasible starting point for national health insurance as highlighted by Osaki et al. (2010) is low cost Community Based Health Insurance (CBHI), a subject that the researchers sought to research on. Determining the demand of such low cost health insurance is important to establish the feasibility of such schemes.

This study aimed to determine the demand and thus the feasibility of CBHI in rural areas by investigating the rural households' willingness to pay for CBHI. The study also examined the sustainability of CBHI given the low incomes in rural areas. CBHI has been successful in South Asia, East and West African countries where it provides financial coverage for those in rural areas and in informal employment (Bhageerathy et al., 2017; Mogessie et al., 2017; Ranabhat et al., 2017; Umeh et al., 2017; Workneh et al., 2017). Its feasibility and sustainability in Zimbabwe would provide a springboard to launch such schemes amongst communities with common solidarity which would then be integrated and harmonized into a National Health Insurance scheme which has lower levels of adverse selection. To the best of our knowledge, there is no other study of willingness to pay for health insurance and sustainability of CBHI in Zimbabwe.

This paper seeks to answer the following research questions for a typical rural community in Zimbabwe:

1. What is the willingness to pay for CBHI?

2. To what extent in CBHI feasible?

3. Can CBHI be sustainable?

4. Does CBHI improve health outcomes?

\section{Literature Review}

Health insurance can either be voluntary or involuntary. Whilst national health insurance is compulsory to all citizens, social health insurance is targeted towards certain groups who will benefit exclusively. Voluntary health insurance includes private health insurance and CBHI schemes. According to Lofgren et al. (2008), voluntary health insurance has potential to increase considerably the healthcare visits and reduce out-of-pocket spending. In addition to that, it leads to less self-treatment which involves purchase and use of drugs without medical advice from professionals. Although current evidence points out that compulsory health insurance increases healthcare utilisation more than voluntary health insurance (Lofgren, 2008), we conducted this research as a feasibility study for CBHI. We are optimistic that in the medium to long run, the government can be able to harmonise the fragmented CBHI schemes into one national health insurance scheme as pointed out by Osaki et al. (2010).

The CVM has been used in valuation of public goods for a period now spanning 35 years (Mogessie et al., 2017; Babatunde et al., 2016; Onwujekwe et al., 2010; Asfaw et al., 2008; Masanjala and Phiri, 2007; Venkatachalam, 2004; Wattage, 2002). Common ways of value elicitation through CVM are Open Ended Bidding (OEB) and Dichotomous Choice (DC) (Mogessie et al., 2017; Asfaw et al., 2008; Wattage, 2002). OEB has the advantage of lower WTP values when compared to its DC counterpart (Yu and Abler, 2010). Besides eliciting higher WTP values, the DC format also has the weakness of more yes saying instead of 
respondents stating what they are actually willing to pay. Furthermore, DC formats often yield more protest zeros when bids are very high because they do not offer the flexibility of the respondents stating their own values (Yu and Abler, 2010). CBHI schemes are formed on the premise that communities themselves know what kind of healthcare packages they can afford and as such, OEB is the most appropriate format for eliciting WTP for low cost insurance.

A number of WTP studies have been carried out in developing countries including Bangladesh, Ethiopia, India, Malawi, Namibia, Sudan and Vietnam (Basaza et al., 2017; Mogessie et al., 2017; Ahmed et al., 2016; Bawa and Ruchita, 2011; Onwujekwe et al., 2009; Asfaw et al., 2008; Lofgren et al., 2008; Masanjala and Phiri, 2007). Basaza et al., (2017) found of individual income, household size, insurance cover and religion significantly determining WTP in Sudan. Onwujekwe et al. (2009) found economic status and place of residence significantly influencing WTP for CBHI membership in Nigeria. This is corroborated by Ahmed et al. (2016) in Bangladesh. Although our study is carried out in rural areas, regression analysis of WTP will be controlled for village and provincial divisions. Onwujekwe et al. (2009) and Lofgren et al. (2008) proceed to suggest augmentation of CBHI funds to ensure sustainability of CBHI schemes. This implies that it is common to find current health expenditures being less than proposed contributions.

Asfaw et al. 2008, Lofgren et al. (2008) investigated the impact of age on WTP in Namibia and India respectively. Lofgren et al. (2008) found older households stating lower WTP values than younger households whilst Asfaw et al. (2008) found a quadratic relationship between age and WTP values that is concave in shape. Asfaw et al. (2008) found that on average, households are willing to insure 4 individuals although they also found household size having no significant relationship with WTP. Lofgren et al. (2008), Asfaw et al. (2008) found health status positively influencing WTP values such that households that have members with health problems stated higher WTP values. Lofgren et al. (2008), Bawa and Ruchita (2011), Asfaw et al. (2008) all found income positively related to WTP values whilst the former also discovered that lack of access to health centres resulted in suppressed WTP values.

Mogessie et al. (2017), Lofgren et al. (2008), Onwujekwe et al. (2009), Bawa and Ruchita (2011), Asfaw et al. (2008) all found WTP values increasing with more education whilst only Asfaw et al. (2008) finds sexual status not significantly affecting WTP. Average WTP values are generally lower with Onwujekwe et al. (2009) reporting an average of $\$ 1.50$ and Babatunde et al. (2016) reported $\$ 1.10$ in Nigeria. Asfaw et al. (2008) found an average WTP value of $\$ 6.60$ whilst Onwujekwe et al. (2009) found an average of $\$ 4.37$ for Namibian and Nigerian urban areas respectively. These are all relatively higher however, compared to actual premiums being paid in Indian low cost CBHI schemes ranging from $\$ 0.50$ to $\$ 2.50$ (Carrin, 2003; Devadasan et al., 2004). The main challenge with these Indian CBHI schemes has been sustainability. This is brought about by the challenges in risk pool sizes, premium charges and management. In order for the scheme to attract more membership, the premiums have to be very low.

Bawa and Ruchita (2011) found the electronic media as the main source of awareness that encourages CBHI membership in India. Reported $\mathrm{R}^{2}$ values are very low as pointed out in Wattage (2002) with Onwujekwe et al. (2009) reporting 17 percent whilst Asfaw et al. 2008 reports 6 percent indicating lack of validity for the latter. These factors form the basis of our estimation model as we seek to establish predictors of WTP values in Zimbabwe which are conflicting in these prior studies.

There are three popular CBHI models that have been successfully implemented in India (Bhageerathy et al., 2017; Raza et al., 2016; Devadasan et al., 2004). In the first type, the hospital that provides healthcare also runs the insurance. This has a potential of the problem of supplier induced demand prevalent in the health sector. In the second type, a voluntary organization that coordinates the CBHI scheme, for example and NGO, is the insurer. It purchases care from independent healthcare providers. Under the third and more popular type, the voluntary organization plays the role of an agent. It purchases insurance from insurance companies and also purchases care from healthcare providers.

\section{Methodology}

The research was conducted in two phases. The first phase involved establishing the willingness to pay for CBHI. The second phase was a 3 year follow up study on feasibility and sustainability of CBHI

\subsection{Phase 1: Willingness to Pay}

3.1.1. Research Design

After obtaining Medical Research Council of Zimbabwe approval as well as clearance from state and public health authorities, the researchers carried out a 2 stage sampling procedure on villagers residing in Musana and Domboshava rural areas, with a population which is largely unemployed and reliant on subsistence 
agriculture. In the first stage, we conveniently selected 14 Villages easily accessible by road before systematically selecting villagers for interviews. The survey carried out between February and March 2014 included questions on demographic characteristics, health expenditure, Willingness to Pay (WTP) for health insurance, sources of income and consumption expenditures. We used personal interviews which have the advantages of face-to face contact, increasing engagement and awareness by interviewee, reduces misunderstanding, and makes spontaneous questions possible. These issues were important since there was need to explain the healthcare package under the scheme and also to probe monthly expenditures.

\subsubsection{Analysis}

Suppose that an individual derives utility from buying (and thus consuming) a bundle of two goods; health insurance premiums and a composite good of all other affordable commodities denoted by $x_{1}$ and $x_{2}$ respectively. The utility function can be written as:

$$
U(x)=U\left(x_{1}, x_{2}\right)
$$

The WTP model for health insurance is based on the supposition that the utility derived by the individual from being covered by health insurance, $U_{1}$ is greater than the utility derived when he is not insured $U_{0}$.The stated WTP thus represents the individuals utility derived from contributing and thus belonging to the CBHI scheme.

The willingness to pay of individual $i$ for health insurance is given by:

$$
W T P_{i}=X^{\prime} \beta+\varepsilon_{i}
$$

Where $X$ is a vector of explanatory variables, $\beta$ is a vector of coefficients to be estimated, $\varepsilon$ is a random error term assumed to be randomly and independently distributed with mean zero and constant variance, $\sigma^{2}$.

To analyse the determinants of WTP, we used the Poisson Regression Model (PRM). The PRM is used in cases where the dependent variable takes on relatively few values including zero and also where data is assumed to follow a poisson distribution. With a large number of zero value responses, use of linear regression models may lead to negative WTP predicted values, a situation we thus tried to avoid since an exponential function of the PRM always yields non zero predicted values. In addition to that, we also cannot take a logarithm of such data due to the zero values. The poisson distribution has a robustness property in that whether or not the distribution holds, asymptotically normal estimators of the $\beta_{j}$ can be obtained (Wooldridge, 2004).

The PRM models the expected value of an exponential function:

or in short

$$
E\left(y / x_{1}, x_{2}, \ldots, x_{k}\right)=e^{\left(\beta_{0} x_{1}+\beta_{1} x_{1}+\ldots+\beta_{k} x_{k}\right)}
$$

$$
E(y / \boldsymbol{x})=e^{(\boldsymbol{x} \boldsymbol{\beta})}
$$

Equation 4 is nonlinear in its parameters so we cannot use linear regression methods, but will rely on quasi-maximum likelihood estimation. The poisson distribution is entirely determined by its mean so that only $E(y / \boldsymbol{x})$ is specified (Wooldridge, 2004). It has the same form as in equation 4, thus, the probability that $y$ equals the value $h$ conditional on $\boldsymbol{x}$ is:

$$
P(y=h \mid \boldsymbol{x})=e^{\left(-e^{\boldsymbol{x} \boldsymbol{\beta}}\right)\left(e^{\boldsymbol{x} \boldsymbol{\beta}}\right)^{h}} / h !, h=0,1, \ldots,
$$

Equation 6 is thus our WTP estimation equation:

$\mathrm{P}(\mathrm{WTP}=\mathrm{h} \mid \mathrm{X})=\mathrm{F}\left(\mathrm{AGE}, \mathrm{AGE}^{2}, \mathrm{EDU}\right.$, INCOME, HHSIZE, RELIGION, DIST, COST, INFO, POLY, VILLAGE, PROVINCE, DRUGS, VISITS, MHE, INCPROJ, SEX)

Poisson Regression was used to analyse the determinants of WTP using STATA 10 software.

\subsection{Phase 2: Community Based Health Insurance Scheme}

\subsubsection{Research Design}

To determine sustainability of CBHI, we offered a CBHI scheme to the 121 families from 14 Villages purposively selected from Musana and Domboshava rural areas on the basis of ease of accessibility by road. Qualitative data was collected during meetings and interactions with research participants. Quantitative data was obtained from clinic cards and receipts from health centres. 
Premiums were to be charged per household as established from the WTP study in phase one. Each household was limited to five members. The next five members were accepted but only if they contributed as a separate household.

Sustainability was measured by the extent to which scheme contributions matched healthcare expenditures of research participants. A financial gap results from contributions falling short of medical expenditures and previous studies have established a range of $60 \%$ to $100 \%$ short fall (Ahuja and Jutting, 2003; Devadasan et al., 2004). The larger the gap, the less the sustainability. The researchers did not limit the type of ailment covered, but instead, agreed a maximum cover of $\$ 100$ per month with the CBHI membership. Funds from the Research Council of Zimbabwe were used to finance the financial gap during the research project on top of research expenses.

\subsubsection{Data Analysis}

Data was analysed in Microsoft excel. Qualitative data was compiled and summarised through triangulation.

4. Results

Results are presented in two sections for each of the two phases.

\subsection{Willingness to Pay Study}

Table 3 presents the socio-demographic characteristics of the sample. 121 household heads of mean age 42.1 years were interviewed for personal information as well as that related to their household, monthly health and consumption expenditures. On average, each household had 6 members. It was difficult to get the monthly income from the respondents due to fluctuations in incomes so we ended up eliciting for monthly expenditure. An average household has a monthly expenditure of $\$ 55$. The monthly expenditure however, ranged from $\$ 15$ to $\$ 250$.

Table 3. Demographic characteristics of respondents

\begin{tabular}{|l|c|}
\hline Characteristics & 121 \\
\hline Number of respondents & $42.1(15.6)$ \\
\hline Mean Age, years (SD) & $5.5(1.8)$ \\
\hline Mean household size, n(SD) & $55(15,250)$ \\
\hline Monthly expenditure, US\$ Mean (min, max) & \\
\hline Income sources n (\%) & 72.4 \\
\hline Agriculture & 3.4 \\
\hline Formal Employment & 37.9 \\
\hline Other Informal Work & \\
\hline Education (\%) & 9.9 \\
\hline At least High School & 61.2 \\
\hline Secondary school & 24 \\
\hline Primary school & 4.9 \\
\hline Never attended school & 66.1 \\
\hline Sex (\%) & 33.9 \\
\hline Male & \\
\hline Female & 36.4 \\
\hline Religion (\%) & 63.6 \\
\hline Apostolic and Traditional & 16.5 \\
\hline Non Apostolic and Traditional & 83.5 \\
\hline Membership to income generating project (\%) \\
\hline Members & \\
\hline Not members & \\
\hline
\end{tabular}

Some 72.4 percent of the households relied on subsistence agriculture for a living whilst 37.9 percent were involved in informal income generating activities like construction and welding, shoe mending; and 3.4 percent of the households got support from someone formally employed in the household. Less than 5 percent of the respondents had never attended school whilst 70 percent had attended at least secondary education. The 66 percent of the interviewees were male whilst 63.6 percent were non-apostolic and non-traditional in religion. Only 16.5 percent of the individuals reported their households in income generating project group schemes. 
Table 4. Willingness to Pay Descriptive statistics

\begin{tabular}{|c|c|c|c|c|}
\hline Variable & Mean & SD & Minimum & Maximum \\
\hline WTP \$ & 5.43 & 4.1 & 0 & 15 \\
\hline Current Monthly health expenditure & 11.61 & 22.8 & 0 & 180 \\
\hline Average drug expenditure per visit & 4.2 & 4.7 & 0 & 30 \\
\hline Average healthcare visits per month & 2.4 & 1.7 & 0 & 5 \\
\hline Membership to CBHI & $(\%)$ & & & \\
\hline Yes & 93.4 & & & \\
\hline No & 6.6 & & & \\
\hline Preferred Fund Manager & $(\%)$ & & & \\
\hline Health Provider & 23.1 & & & \\
\hline Community administrator & 76.9 & & & \\
\hline
\end{tabular}

Table 4 shows information related to the healthcare expenditure, WTP values and preferred fund managers for the CBHI scheme. Some 93.4 percent of the sample indicated willingness to join the CBHI scheme. Those who indicated zero willingness to pay values indicated that they neither desired nor wanted to use the healthcare package offered under the CBHI due to religious grounds. After explaining the 3 different methods under which CBHI funds can be managed, 76.9 percent of the respondents indicated the desire for community management whilst 23.1 percent would rather have the fund managed by the healthcare provider. Those who preferred a health provider managed fund cited the credibility of government officials to be trusted with public funds compared to their village counterparts who have abused similar funds in the past. However, 35 percent of those who indicated preference for community management also indicated lack of trust on their village counterparts especially headmen. They however, indicated that they would prefer someone with valuable household assets to manage the funds for the reason that the scheme can recover its resources in the case of mismanagement. Few indicated being comfortable with headmen due to their status whilst others suggested women be entrusted for the reason that they are more risk averse in terms of short term investments of the fund when compared to their male counterparts. The mean willingness to pay for CBHI was $\$ 5.43$ (median $\$ 5$ ) for the sample with minimum values of $\$ 0$ to a maximum of $\$ 15$. Current monthly healthcare expenditures of the respondents' households range from $\$ 0$ to $\$ 180$ with a mean of $\$ 11.61$. This indicates a short fall of $\$ 6.18$ when compared to what households were willing to pay in insurance. The current average drug expenditure per visit was $\$ 4.20$ with a maximum value of $\$ 30$. On average, each household makes 2.4 visits per month with 5 being the highest number of visits per month from a household.

Table 5. Determinants of Willingness to Pay for Community Based Health Insurance

\begin{tabular}{|c|c|c|c|}
\hline Variables & Poisson coefficient & STD Error & Z-Value \\
\hline Age & 0.212 & 0.025 & $8.65 * * *$ \\
\hline Age2 & -0.003 & 0.0002 & $-8.81 * * *$ \\
\hline \multicolumn{4}{|c|}{ Distance } \\
\hline Close & - & - & - \\
\hline Too far & -0.068 & 0.104 & -0.65 \\
\hline \multicolumn{4}{|c|}{ Religion } \\
\hline Other* & - & - & - \\
\hline Trad/Apostolic & 0.068 & 0.092 & 0.73 \\
\hline \multicolumn{4}{|c|}{ Income } \\
\hline Farming & - & - & - \\
\hline Farming Plus & 0.030 & 0.102 & 0.290 \\
\hline \multicolumn{4}{|c|}{ Cost } \\
\hline Affordable* & - & - & - \\
\hline Unaffordable & -0.0589 & 0.111 & -0.53 \\
\hline \multicolumn{4}{|c|}{ Education } \\
\hline No education* & - & - & - \\
\hline Primary & 0.816 & 0.324 & $2.52 * *$ \\
\hline Secondary & 1.023 & 0.311 & $3.29 * * *$ \\
\hline Higher education & 1.253 & 0.331 & $3.79 * * *$ \\
\hline \multicolumn{4}{|c|}{ Information Access } \\
\hline Rare* & - & - & - \\
\hline Frequent & .216 & .096 & $2.24 * *$ \\
\hline \multicolumn{4}{|c|}{ Respondents' Sex } \\
\hline Female & - & 1 & - \\
\hline
\end{tabular}




\begin{tabular}{|l|c|c|c|}
\hline Male & 0.059 & 0.090 & 0.66 \\
\hline \multicolumn{3}{|c|}{ Household Head Sex } \\
\hline Female & - & - & - \\
\hline Male & 0.183 & 0.098 & $1.87^{*}$ \\
\hline \multicolumn{4}{|c|}{ Income Project } \\
\hline No & - & - & 1 \\
\hline Yes & -0.104 & 0.120 & -0.87 \\
\hline Monthly health Exp & 0.001 & 0.002 & 0.89 \\
\hline Monthly visits & 0.049 & 0.026 & $1.87^{*}$ \\
\hline Household Size & -0.031 & 0.028 & -1.13 \\
\hline
\end{tabular}

Table 5 shows the results of multivariate analysis of the determinants of WTP for CBHI in terms of probability at 1,5 and 10 percent levels of significance denoted by $* * * * *$ and $*$ respectively. Age, education, access to educative information and to a lesser extent the number of healthcare visits and sex of the household head are significant determinants of WTP values for CBHI. Age of the respondent significantly influences the WTP values at the 1 percent level. However, age squared which was incorporated to investigate the existence of a quadratic relationship is also significant at 1 percent. The fitted values were plotted in STATA 10 to display this relationship as depicted in figure 1 which shows WTP values increasing until mid-40s and then declining thereafter, probably depicting the respondents' declining ability to pay as well.

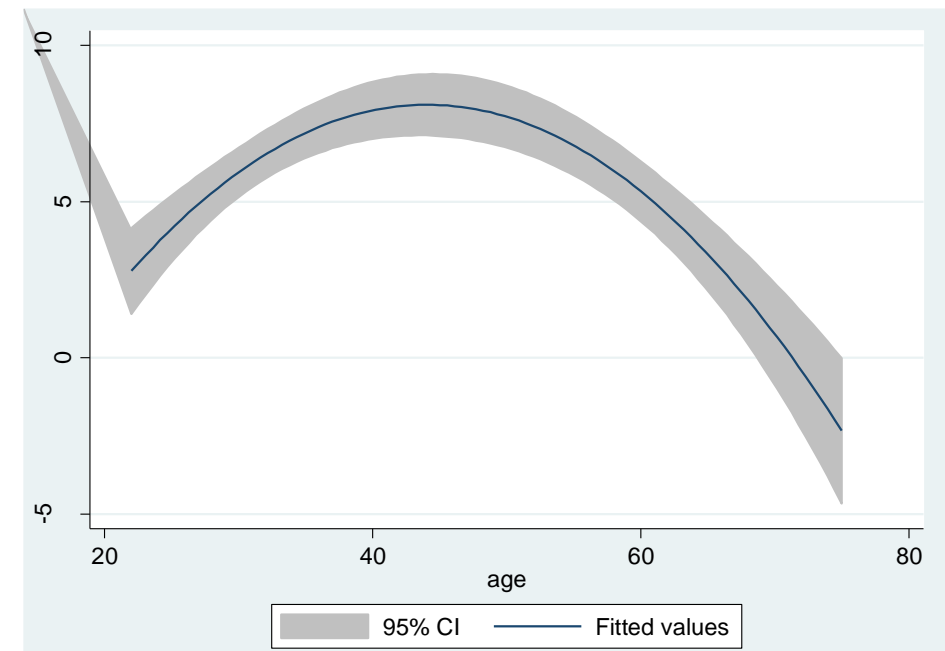

Figure 1. Quadratic Relationship between age and Willingness to Pay

Primary, secondary and higher education levels are all significant predictors of higher willingness to pay when compared to no education 5 percent, 1 percent and 1 percent levels respectively. Since coefficients from a PRM are interpreted in terms of percentages, the results imply that those with primary education report WTP values that are $82 \%$ higher than those with no formal education. Those with secondary and higher education express WTP values that are 102 percent and 125 percent higher than the uneducated respectively. Access to educative programmes in the electronic media as proxied by frequency to access the electronic media significantly influences WTP values at 5 percent level of significance. The WTP values of those who listen to the radio are higher than those who rarely access the electronic media by about 21.6 percent.

The average number of healthcare visits and the sex of the household head are also significant predictors of WTP values, albeit, at the 10 percent level. The WTP values reported by male headed households are 18.3 percent higher than those reported by their female counterparts whilst households who make one more healthcare visit overstates its WTP values by about 4.9 percent.

\subsection{Community Based Health Insurance Scheme}

\subsubsection{Scheme Acceptability}

Although a total of 121 households had participated in the willingness to pay study, the researchers had challenges in recruiting study participants actually willing to commit to the community based health scheme. Villagers in most wards had high emotions stemming from their losses from fraudulent schemes running at the same time awareness campaigns for this study were conducted. In Domboshava, villagers indicated a scheme that had conned them of their indigenous chickens and they were no longer interested in 
contributory schemes. In Musana, villagers had just lost hundreds of dollars from an agricultural input and insurance scheme. Due to the contaminated environment, the researchers were only able to recruit 32 households of which nine dropped out or were released from the scheme due to failure to contribute set agreed premiums during the 3 year follow up phase. As figure 2 shows, the initial recruitment in April 2014 was 29 households. The number fell to 28 between October 2014 and May 2015. It fell further to 23 between May 2015 and March 2016 before 3 new households joined increasing the number to 26 in the same period. The number fell to 23 by the end of the last evaluation period of April 2016 to November 2016. In addition to that, 38.8 percent of the households interviewed indicated lack of ability to pay constant premiums due to their lack of income generating projects which highlights lack of ability to pay for unemployed rural residents.

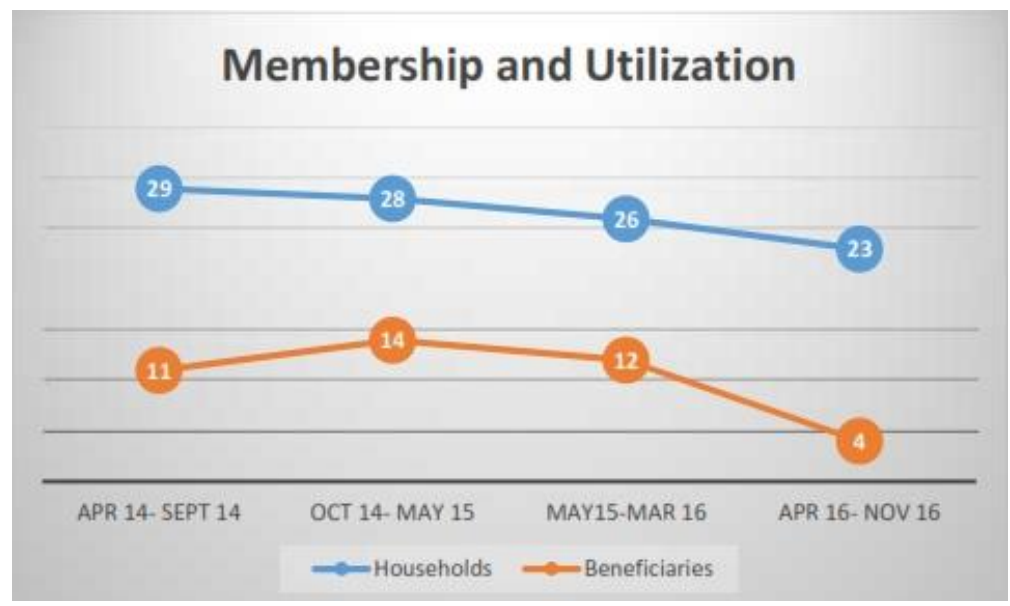

Figure 2. Scheme Membership and Utilization

\subsubsection{Community Based Health Insurance Scheme Model}

The households enrolled in the scheme were mentored on how to run the insurance scheme as a cooperative with training from the Ministry of SMEs from Bindura provincial office. The training enabled the recruited households to be organised as a community run CBHI scheme with a constitution for which members would abide to. The constitution specified amongst other things:

1. The scheme's management committee consisting of a Chairman; Vice Chairman, Treasurer and Secretary

2. A Technical advisory committee

3. Monthly premiums set at $\$ 2.00$ to attract membership

4. Frequencies for meetings

5. Reimbursement procedures

6. Penalties for failure to pay or account for money advanced by the scheme

Researchers provided training in conflict management, accounting and procurement for four management committee members of the scheme.

\subsubsection{Sustainability: Adverse Selection}

Ten percent of the respondents indicated reservation over other members joining the scheme whom they viewed as high end users of healthcare and they did not see themselves nor their household members benefiting in the future as they feared funds would have been run down. This is a typical case of adverse selection were individuals at low risk of falling ill drop out of an insurance scheme leaving only the high risk individuals in the scheme. Two patients consistently benefited from the scheme at least twice during the two reporting periods October 2014 to May 2015 and May 2015 to March 2016. This provides support to the households who dropped out that certain individuals in the scheme had an expected high need for health expenditures. Such a scenario in which high risk individuals join and low risk individuals do not, leads to collapse of health insurance schemes, and in this case, compromises its sustainability. The scheme members had provided for this in their constitution by putting a maximum cap on the amount that an individual can spend in a given month set at $\$ 100$.

\subsubsection{Sustainability: Moral hazard}

Besides the two individuals mentioned above, at least 5 beneficiaries skipped the referral system which is public sector based opting to go to private providers instead. Such practises would not have been possible had they been paying for themselves and such behaviour again compromises sustainability. 


\subsubsection{Sustainability: Financial Gap}

Figure 3 shows the contributions, medical expenses and financial gaps for the CBHI scheme over the 3 year follow up period. Subscriptions fell from a high of $\$ 351.00$ between April and September 2014 to $\$ 235$ in the last reporting period. Medical expenses rose from $\$ 554.90$ to a peak of $\$ 705.50$ between October 2014 and May 2015 and falling to $\$ 226.40$ in the last reporting period. The financial gap rose from $\$ 203.90$ between April and September 2014 to $\$ 447.00$ between October and May 2015 before translating to a surplus of $\$ 8.60$ between April and November 2016. The trend line indicates a falling financial gap during the 3 year follow up study suggesting the possibility of sustainability in the long run.

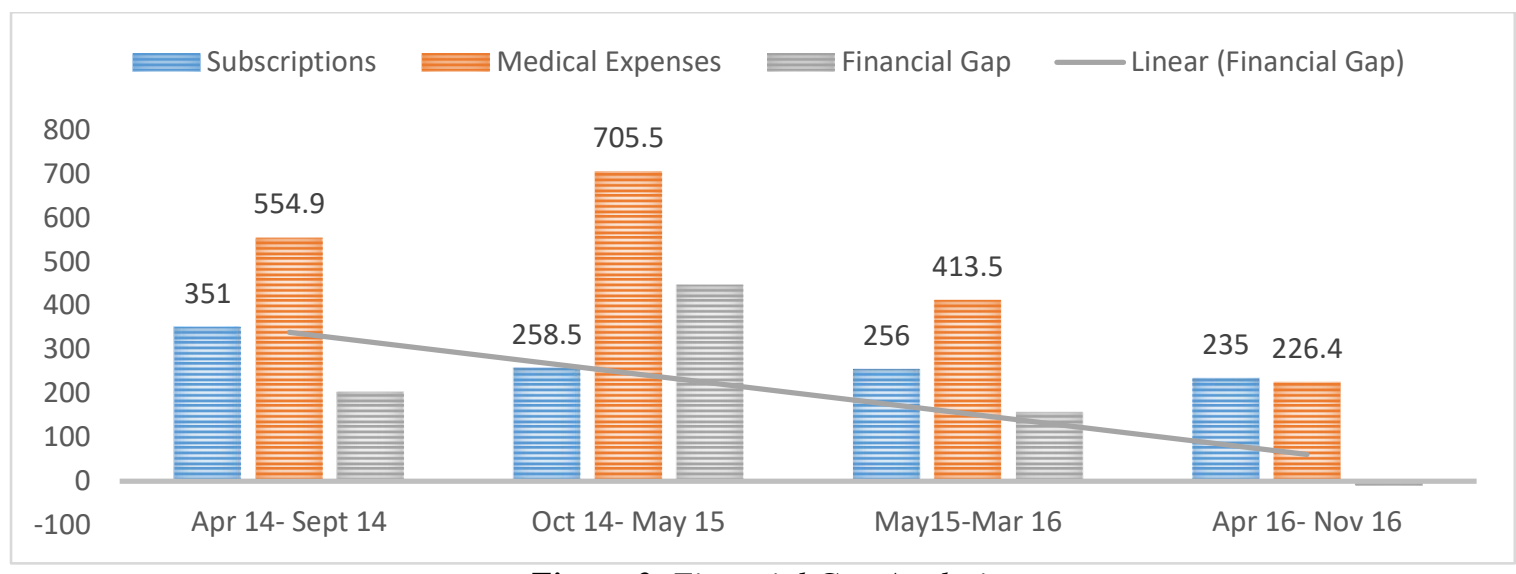

Figure 3. Financial Gap Analysis

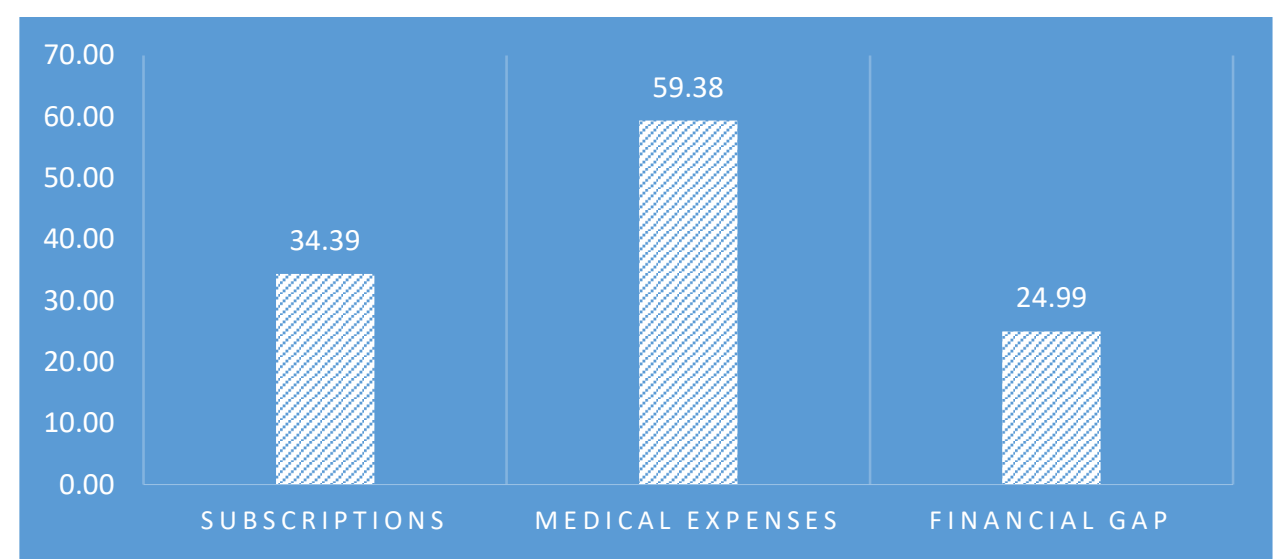

Figure 4. Average monthly subscriptions, medical expenses and financial gap

Figure 4 shows the average monthly subscriptions, medical expenses and financial gap over the 3 years. The average monthly contributions amount to $\$ 34.39$ against monthly expenses of $\$ 59.38$ amounting to a monthly financial gap of $\$ 24.99$ or 42 percent. This figure is comparable to financial gaps established in CBHI success stories in India ranging between 40 percent and 60 percent which is normally funded by donations from well-wishers or the government. The CBHI scheme managed to start an income generating project by end of project which involves rearing indigenous chicken and goats to finance the financial gap. Its ability to close the gap had not yet been established by the end of the project.

\subsubsection{Can Community Based Health Insurance Improve Health Outcomes?}

At inception of the CBHI scheme, the members indicated that they failed to utilize health services due to reasons in table 6. Forty five percent indicated challenges to afford bus fare to healthcare facilities even in cases where healthcare is free like maternity, child care and the elderly. Due to the nature of receipts from commuter omnibuses, the researchers were not able to reimburse the participants and resolved that their own contributions take care of transport and other administrative expenses for the scheme. Seventy two percent indicated challenges in meeting healthcare costs. Respondents indicated that sometimes the public clinics and hospitals fail to provide medication for the elderly, children and pregnant women, due to stock outs and they are referred to private pharmacies for which they could not afford. 
As indicated in figures 3 and 4, the CBHI scheme could meet medical expenditures if the gap of 42 percent can be closed either by government, well-wishers or an income generating activity for the community. CBHI schemes could also improve health outcomes due to insurance against impoverishment. Table 4.4 highlights this notion as 66 percent of respondent indicated that most of the time, they had to prioritise other household needs like fees and food. The CBHI scheme enabled the households to access healthcare at affordable premiums.

Table 6. Reasons for failing to utilize healthcare

\begin{tabular}{|l|c|c|c|c|c|c|}
\hline \multirow{2}{*}{} & \multicolumn{2}{|c|}{ never } & \multicolumn{2}{c|}{ few times } & \multicolumn{2}{|c|}{ most times } \\
\cline { 2 - 8 } & $\mathrm{n}$ & $\%$ & $\mathrm{n}$ & $\%$ & $\mathrm{n}$ & $\%$ \\
\hline Failure to raise bus fare & 7 & 24.1 & 9 & 31.0 & 13 & 44.8 \\
\hline Lack of medical treatment fees & 2 & 6.9 & 6 & 20.7 & 21 & 72.4 \\
\hline Money available has other commitments: food, fees & 0 & 0.0 & 11 & 37.9 & 19 & 65.5 \\
\hline
\end{tabular}

\subsubsection{Current Challenges}

The year 2016 was characterised by cash shortages which affected contributions to the health scheme as well as payment for medical care by the researchers. A particular case occurred in October when a member had to return home as the sole health provider offering $X$ rays in Bindura was not accepting bank cards "swiping". This worsened the patient's case as he could not raise the bus fare required to return the next day. The situation might improve in the future with the injection of bond currency as well as adoption of plastic money by service providers.

\section{Discussion}

The study sought to establish: (i) acceptability and willingness to pay for insurance contributions and what factors determine its elasticity; (ii) the extent to which CBHI increase healthcare access and utilization in Zimbabwe; and (iii) the sustainability of CBHI in Zimbabwe. The study established an average WTP of $\$ 5.43$ for CBHI. Age, education, access to educative information and healthcare need and sex of the household head are significant determinants of WTP values for CBHI. These findings are comparable to other studies conducted in low income settings (Basaza et al., 2017; Mogessie et al., 2017; Babatunde et al., 2016; Ahmed et al., 2016; Dror et al., 2016a; Onwujekwe et al., 2010; Lofgren, 2008; Aswaf, 2008, Masanjala and Phiri, 2007). Factors that influence membership to schemes include distance, quality of care and trust. Education and access to information are also significant predictors of WTP values. This is in consistence with findings from other developing countries (Umeh et al., 2017; Mogessie et al., 2017; Workneh et al., 2017; Ahmed et al., 2016; Lofgren et al., 2008; Onwujekwe et al., 2009; Bawa and Ruchita, 2011; Asfaw et al., 2008). This implies that households with lower education level are likely to be unable to join CBHI schemes due to the lower values they are prepared to pay.

Failure of members to pay premiums as established by the WTP study led to financial gaps of the CBHI scheme averaging 42 percent. The shortfall of CBHI funds in meeting community healthcare needs is a serious threat to sustainability of the schemes (Carrin, 2003; Devadasan 2004; Tabor 2005). Indian CBHI schemes survive this huddle mainly because they are initiated in societies with income generating capacities (Panda et al., 2014; Carrin, 2003) and this also facilitates attainment of inclusiveness in the schemes and equity. Members are usually involved in group projects that generate incomes from which premiums are generated before the share of proceeds. This also presents an opportunity for developmental organisations as it highlights the need to promote income generating projects for such groups.

An alternative to avoid the huge financial gaps in CBHI involves considering different contribution designs in terms of enrolment units. Instead of enrolling households, villagers could be enrolled on an individual basis like in private insurance. This has the problem of adverse selection due to high costs on the household level (Devadasan 2004 et al., 2003; Carrin, 2003). Enrolment can also be on a village or income generating group project basis.

CBHI has potential to improve healthcare utilization and health outcomes. Financial problems indicated by study participants at inception: failure to get money for transport when ill; failure to get money to pay for healthcare and medication; and financial impoverishment due to other competing needs like fees and food, are all neutralised by a health insurance scheme. The key, however, is to have a larger coverage so as to share risks across both high risk households and low risk households. Low uptake of CBHI schemes is common in other African countries which Mladovsky and Ndiaye (2015) attribute to lack of solidarity. We support their recommendation that policy makers engage communities in educating them on benefits of pooling financial resources and also to develop an understanding of their expectations. Umeh et al. (2017) review CBHI evidence 
from low to middle income countries and established that uptake is positively related to socioeconomic status and that the poor were not able to pay premiums. They suggest flexible payment plan like instalments, subsidizing the poor and removing co-payments.

Our study, however, established a higher retention rate at 79 percent, than established by Panda et al., (2016) in India. We attribute this to a broader benefits package in the scheme which results in competitiveness of the CBHI scheme when compared with alternatives. Panda et al. (2016) find evidence of the negative effects of in appropriate packages in India which is also unearthed by Dror et al. (2016a) across low and medium income countries. The latter also found evidence on the negative effects of lack of trust amongst membership on enrolment as established in our study. The geographic area covered by researchers had been contaminated by fake and fraudulent insurance schemes which led to a negative attitude against any contributory schemes. Future research needs to evaluate $\mathrm{CBHI}$ in an environment without a history of fraudulent and fake schemes.

Our study is limited in terms of quantifying the impact of CBHI on health outcomes and financial impoverishment. Our qualitative approach of enquiring from the project beneficiaries their perceived improvements could be biased because it is possible the beneficiaries wanted the project to continue and would thus view negative answers as threatening funding. Other researchers have used randomised experiments to avoid such bias. Ji et al. (2017) used a cluster randomised design and found that CBHI reduced catastrophic health expenditures in Burkina Faso. Dror et al. (2016b) also used a cluster randomised design and came to the same conclusion for India as well as establinshing lower prevalence of self medication amongst those supported by CBHI. Raza et al. (2016), however, failed to establish a significant impact of CBHI in Uttah Pradesh and Bihar, India, using randomised control trials. Future research, funds permitting, needs to consider randomisation to improve on our findings and quantify the impact of CBHI in Zimbabwe.

\section{References}

Ahmed, S., Hoque, M.E., Sarker, A.R., Sultana, M., Islam, Z., Gazi, R. and Khan, J.A., 2016. Willingness-topay for community-based health insurance among informal workers in urban Bangladesh. PloS One, 11(2), p.e0148211.

Ahuja, R. and Jütting, J., 2003. Design of incentives in community based health insurance schemes (No. 63). ZEF Discussion Papers on Development Policy.

Asfaw, A., Gustafsson-Wright, E. and van der Gaag, J., 2009. Willingness to pay for health insurance: An analysis of the potential market for new low-cost health insurance products in Namibia. Social Science and Medicine, 69(9), pp.1351-1359.

Babatunde, R.O., Oyedeji, O.A., Omoniwa, A.E. and Adenuga, A.H., 2016. Willingness-to-pay for community based health insurance by farming households: a case study of Hygeia community health plan in Kwara state, Nigeria. Trakia Journal of Sciences, 14(3), pp.281-286.

Basaza, R., Alier, P.K., Kirabira, P., Ogubi, D. and Lako, R.L.L., 2017. Willingness to pay for National Health Insurance Fund among public servants in Juba City, South Sudan: a contingent evaluation. International Journal for Equity in Health, 16(1), p.158.

Bawa, S.K. and Ruchita, M., 2011. Awareness and willingness to pay for health insurance: an empirical study with reference to Punjab India. International Journal of Humanities and Social Science, 1(7), pp. 100108.

Bhageerathy, R., Nair, S. and Bhaskaran, U., 2017. A systematic review of community-based health insurance programs in South Asia. The International journal of health planning and management, 32(2).

Carrin, G., 2003. Community based Health Insurance Schemes in Developing Countries: facts, problems and perspectives. Geneva, WHO.

Devadasan, N., Ranson, K., Van Damme, W. and Criel, B., 2004. Community health insurance in India: an overview. Economic and Political Weekly, pp.3179-3183.

Dhliwayo, R., 2001. The Impact of Public Expenditure Management Under ESAP on Basic Social Services: Health and Education. SAPRI.

Dror, D.M., Hossain, S.S., Majumdar, A., Koehlmoos, T.L.P., John, D. and Panda, P.K., 2016a. What factors affect voluntary uptake of community-based health insurance schemes in low-and middle-income countries? a systematic review and meta-analysis. PloS One, 11(8), p.e0160479.

Dror, D.M., Chakraborty, A., Majumdar, A., Panda, P. and Koren, R., 2016b. Impact of community-based health insurance in rural India on self-medication and financial protection of the insured. The Indian journal of medical research, 143(6), p.809.

GoZ, 2010. Medium Term Plan 2011-2015. Harare: Government of Zimbabwe. 
Muchabaiwa, L., Chigusiwa, L., Bindu, S., Mudavanhu, V., Damiyano, D. and Mushanyuri, B.E., 2017. Feasibility and Sustainability of Community Based Health Insurance in Rural Areas. Case Study of Musana, Zimbabwe. Expert Journal of Finance, 5, pp. 73-85.

GoZ, 2016. Zimbabwe National Health Accounts 2015. Harare: Ministry of Health and Child Care Government of Zimbabwe.

Jan, S., Lee, S.W., Sawhney, J.P., Ong, T.K., Chin, C.T., Kim, H.S., Krittayaphong, R., Nhan, V.T., Itoh, Y. and Huo, Y., 2016. Catastrophic health expenditure on acute coronary events in Asia: a prospective study. Bulletin of the World Health Organization, 94(3), pp.193-200.

Jütting, J.P., 2004. Do community-based health insurance schemes improve poor people's access to health care? Evidence from rural Senegal. World Development, 32(2), pp.273-288.

Lofgren, C., Thanh, N.X., Chuc, N.T., Emmelin, A. and Lindholm, L., 2008. People's willingness to pay for health insurance in rural Vietnam. Cost Effectiveness and Resource Allocation, 6(1), p.16.

Masanjala, W. and Phiri, I., 2007. Willingness to Pay for Health Insurance in Malawi. University of Malawi, Department of Economics.

Mladovsky, P. and Ndiayeii, P., 2015. Solidarity in community-based health insurance in Senegal: Rhetoric or reality?. African Health Monitor, 20, pp.20-26.

Mogessie, E.M. and Bekele, G., 2017. Households' Willingness to Pay for Community Based Health Insurance Scheme: in Kewiot and EfratanaGedem Districts of Amhara Region, Ethiopia. Business and Economic Research, 7(2), pp.212-233

Nanda, P., 2002. Gender dimensions of user fees: implications for women's utilization of health care. Reproductive health matters, 10(20), pp.127-134.

Ncube, M., 2000. Employment, Unemployment and the Evolution of Labour Policy in Zimbabwe. Zambezia, 27(2), pp. 161-194.

Onwujekwe, O., Okereke, E., Onoka, C., Uzochukwu, B., Kirigia, J. and Petu, A., 2009. Willingness to pay for community-based health insurance in Nigeria: do economic status and place of residence matter? Health Policy and Planning, 25(2), pp.155-161.

Osaki, J., D. Altman, L. Ekbladh, I. Katz, H. Nguyen, J. Rosenfeld, T. Williamson, and S. Tapera (2010), Zimbabwe Health System Assessment 2010, Abt Associates Inc.

Panda, P., Chakraborty, A., Dror, D.M. and Bedi, A.S., 2013. Enrolment in community-based health insurance schemes in rural Bihar and Uttar Pradesh, India. Health Policy and Planning, 29(8), pp.960-974.

Panda, P., Chakraborty, A., Raza, W. and Bedi, A.S., 2016. Renewing membership in three community-based health insurance schemes in rural India. Health policy and planning, 31(10), pp.1433-1444.

Raza, W.A., Poel, E., Bedi, A. and Rutten, F., 2016. Impact of Community-based Health Insurance on Access and Financial Protection: Evidence from Three Randomized Control Trials in Rural India. Health economics, 25(6), pp.675-687.

Share, F., 2016. Cabinet Okays Health Insurance Scheme. The Herald Newspaper, 25 November.

Staunton, I., 2016. Publishing for Pleasure in Zimbabwe. Wasafiri, 31(4), pp.49-54.

Summers, L.H., 2015. Economists' declaration on universal health coverage. Lancet 2013, online.

Tabor, S.R., 2005. Community-based health insurance and social protection policy. World Bank, Washington: Social Protection Discussion Paper Series.

Tangcharoensathien, V., Mills, A. and Palu, T., 2015. Accelerating health equity: the key role of universal health coverage in the Sustainable Development Goals. BMC Medicine, 13(101).

Umeh, C.A. and Feeley, F.G., 2017. Inequitable Access to Health Care by the Poor in Community-Based Health Insurance Programs: A Review of Studies from Low-and Middle-Income Countries. Global Health: Science and Practice, 5(2), pp.299-314.

Wattage, P., 2002. Literature Review- Contingency Valuation Method. CVM Report 1, University of Portsmouth Publications.

WHO, 2014. Making fair choices on the path to universal health coverage: Final report of the WHO consultative group on equity and universal health coverage. World Health Organization, Geneva, $\mathrm{CH}$.

Workneh, S.G., Biks, G.A. and Woreta, S.A., 2017. Community-based health insurance and communities' scheme requirement compliance in Thehuldere district, northeast Ethiopia: cross-sectional community-based study. ClinicoEconomics and outcomes research: CEOR, 9, p.353.

$\mathrm{Yu}, \mathrm{X}$. and Abler, D., 2010. Incorporating zero and missing responses into CVM with open-ended bidding: willingness to pay for blue skies in Beijing. Environment and Development Economics, 15(5), pp.535556. 